\title{
PROPERTY CLAIM SERVICES BY COMPOUND POISSON PROCESS AND AN INHOMOGENEOUS LEVY PROCESS
}

\author{
Muhammad Amin S. Murad \\ Dept. of Financial and Banking Sciences, College of Administration and Economics, Cihan University Duhok, Kurdistan region- \\ Iraq-(muhammad.math@uod.ac)
}

\begin{abstract}
:
In this paper, stochastic compound Poisson process is employed to value the catastrophic insurance options and model the claim arrival process for catastrophic events, which were written in the loss period $[0, \mathrm{~m}]$, during which the catastrophe took place. Here, a time compound process gives the underlying loss index before and after $m$ whose losses are revaluated by inhomogeneous exponential Levy process factor. For this paper, an exponential Levy process is used to evaluate the well-known European call option in order to price Property Claim Services catastrophe insurance based on catastrophe index.
\end{abstract}

KEYWORDS: Compound Poisson Process; Catastrophe Insurance Options; Exponential Levy Process; Property Claim Services.

\section{INTRODUCTION}

In the last two decades natural catastrophes took place increasingly and were characterised by a huge amount of losses. Therefore, the insurance companies attempted to securitize the catastrophe risk, by representing exchange traded catastrophe insurance derivatives. For instance, a catastrophe option compiled by property claim service, which is called standardizing option contract, depends on this index of catastrophe losses (Muerman, 2000).

Some reinsurance companies decreased the level of disaster cover they were interested to supply yet others withdrew from the market because of the catastrophe like Storm Daria (Europe 1990), Hurricane Andrew (USA 1992) and the Kobe earthquake (Japan 1995), they were also affected in terms of the profitability and capital bases (Hogg \& Craig, 1995).

At the beginning of 1990s, some banks of investment, especially in the US discovered an alternative way to reinsure product which is catastrophe insurance, traded on a quarterly basis (Jan-Mar, Apr-June, July-Sep and Oct-Dec), introduced by The Chicago Board of Trade in December 1992 (Chistensen \& Schmidli, 2000).

The indices of catastrophe help us to provide a quick valuation of damage which could be less than a week after an event happens and the real paid losses. The Property Claim Services option contract depends on its index which is exercised to pay out in written index-based insurance options. This article introduces the pricing Property Claim Services catastrophe insurance option model, the exponential Levy process employed with parameter $\beta^{*}$ and the Esscher transform which represents Property Claim Services catastrophe index value with parameter $h^{*}$. Further, the research paper prices the PCS index catastrophe event by using European call option in a time during the catastrophe occurs which is called loss period time.

\section{PRELIMINARIES}

Let $X_{t}$ be a stochastic process with stationary and independent increments, assume that $S_{t}$ represents the underlying loss index for catastrophe insurance options with loss period $[0, m)$ and advanced period $[m, T], S_{t}$ has the form:

$$
S_{t}=S_{0} e^{X_{t}}, \forall t \in[0, T]
$$

where $X_{t}$ represents a Poisson process with parameter $\mu$. Therefore, a Poisson model with exponential distributed is of the form

$$
X_{t}=\sum_{n=1}^{N_{t}} Y_{n}, t \in[0, m)
$$

where $X_{t}$ is an inhomogeneous compound Poisson process till $m, N_{t}$ is a time inhomogeneous compound Poisson process with parameter $\mu t$ and the random variable $Y_{t}$ is independent and identical exponential distribution with parameter $\beta$.

Assume that the random variable $Y_{t}$ is an exponential process with parameter $\beta$ and assume that $f(y, \beta)$ denote the exponential distribution with parameter $\beta>0$,

$$
f(x, \beta)=\int_{0}^{\mathrm{x}} \frac{1}{\beta} \mathrm{e}^{-\frac{1}{\beta} \mathrm{y}} \mathrm{dy} \quad x \geq 0
$$

The exponential process $\gamma(t ; \mu, \delta)$ with mean rate $\mu$ and variance rate $\delta$ is a Levy process such as the random variable $\gamma(t ; \mu, \delta)$ which has exponential distribution with mean $t \mu$ and variance $t \delta$.

At $t=1$ :

$$
\mu=\frac{1}{\beta} \quad \& \quad \delta=\frac{1}{\beta^{2}}
$$

Now we are going to take the moment generating function for exponential distribution $f(x, \beta)$.

Moment generating function (mgf) for $X$ is

The (mgf) $M_{X}(t)$ of $X$ is

$$
M_{x}(u)=\frac{\mu}{\mu-u} ; \quad \mu=\frac{1}{\beta} .
$$

$$
M_{X}(t)=(1-\beta t)^{-n}
$$

By using the above formula, we obtain that $X_{t}=\sum_{i=1}^{n} Y_{i}$ has an exponential distribution with parameters $n$ and $\beta$.

\section{ESSCHER TRANSFORM}

A time-honoured tool Esscher transform in actuarial sciences is a dynamic technique where the logarithms of the prices of the primal securities are driven by certain stochastic processes 
with independent and stationary increments in order to price derivative securities.

Assume $f(x)$ to be any probability density function and $h$ be a constant which belongs to a real number s.t

$$
M(h)=\int_{-\infty}^{\infty} e^{h x} f(x) d x
$$

exist. As a function in $x$,

$$
f(x ; h)=\frac{e^{h x} f(x)}{M(h)}
$$

is a probability density and the Esscher transform with parameter $h$ of the original distribution.

From (3.1) and (3.2) we obtain the cumulative distribution

$$
F(x, t ; h)=\frac{e^{h x} f(x, t)}{\int_{-\infty}^{\infty} e^{h v} f(v, t) d v}=\frac{e^{h x} F(d x, t)}{M(h, t)}
$$

This is the revised distribution of $X_{t}$. The corresponding moment generating function is as follows:

$$
M(u, t ; h)=(M(u, 1 ; h))^{t}
$$

In fact, the stock values are internally coordinated, $h$ and $h^{*}$ are equal and the discount price process $\left(e^{-i t} S_{t}\right)$ is a martingale with respect to $h^{*}$ and one easily can show that

$$
i=\ln \left(M\left(1,1 ; h^{*}\right)\right)
$$

where $i$ is a riskless interest rate.

\section{THE MODEL OF INSURANCE OPTION PRICE AND EXPLICIT FORMULA FOR THE EUROPEAN CALL OPTION}

Indeed, we can value different derivative securities, yet in this paper, we chose European call option. Assume that the European call option on $S_{t}$ with the exercise price $K$ and date $T$ is

$$
E^{*}\left[e^{-i t}\left(S_{t}-K\right)_{+}\right]
$$

Let $x_{+}=x$ if $x>0$, and $x_{+}=x$ if $x \leq 0$ with $k=\ln \left[\frac{K}{S_{0}}\right]$.

$$
\begin{gathered}
E^{h}\left(S_{t} I\left(S_{t}>K\right)\right)=\frac{\left(S_{0}\right)^{k} E\left(e^{(k+h) X_{t}} \emptyset\left(S_{t}\right)\right)}{E\left(e^{h X_{t}}\right)} \\
=\frac{E\left(\left(S_{t}\right)^{k} e^{h X_{t}}\right) E\left(e^{(k+h) X_{t}} \emptyset\left(S_{t}\right)\right)}{E\left(e^{h X_{t}}\right) E\left(e^{(k+h) X_{t}}\right)}=E^{h}\left(\left(S_{t}\right)^{k}\right) E^{h+K}\left(\emptyset\left(S_{t}\right)\right) .
\end{gathered}
$$

Assume that $k=1, h=h^{*}$ and $\emptyset(x)=I(x>K)$, using the above formula, we gain

$$
\begin{gathered}
E^{h^{*}}\left(S_{T} I\left(S_{T}>K\right)\right)=E^{h^{*}}\left(S_{T}\right) E^{h^{*}+1}\left(I\left(S_{T}>K\right)\right) \\
=E^{h^{*}}\left(S_{T}\right)\left(1-F\left(T, h^{*}+1, K\right)\right) \\
=e^{r T} S_{0}\left(1-F\left(T, h^{*}+1, K\right)\right) .
\end{gathered}
$$

Here, the price of European call option at $t=0$ is given by

$$
S_{0}\left(1-F\left(T, h^{*}+1, K\right)\right)-e^{-r T} K\left(\left(1-F\left(T, h^{*}, K\right)\right)\right) \text {. }
$$

The value of European call option is used to represent the capped contract at expire day $\mathrm{T}$, with strike value $\mathrm{K}$ and cap price $\mathrm{L}$ is

$$
C\left(T, S_{t}\right)=\min \left(\max \left(S_{t}-E, 0\right), L-K\right) .
$$

Where $S_{t}$ is the property Claim Service loss index at time t.

In (Chang \& Yu, 1996) they proposed a novel randomized operational time approach to price options in information time, also in (Muerman, 2000) by modeling the compound Poisson process represented no arbitrage price processes using Fourier analysis, determined the unique equivalent martingale under which prices in the insurance market were calculated.

Assume that $F_{t}$ is a smallest filtration which holds the available information at $t$ and adapted by the aggregated amount of reported losses $S_{t}$. The price option at time $t \in[0, m]$ can be obtained by

$$
C\left(t, S_{t}\right)=\exp \left(-i(m-t) E^{h^{*}}\left[C\left(m, S_{t}\right) / F_{t}\right]\right)
$$

Where the value of risk Esscher measure is expected by $E^{*}$ and $i$ is risk free interest rate, therefore (4.2) can be written as: $C\left(t, S_{t}\right)=\exp \left(-i(m-t) E^{h^{*}}\left[\min \left(\max \left(S_{m}-E, 0\right), L-K\right) / F_{t}\right]\right)$ Here we need to find the value of $S_{m}$ by using the equation (2.1)

$$
S_{m}=S_{0} e^{X_{t}+X_{m-t}}
$$

where $w_{1}=\ln \left(K / S_{0} e^{X_{t}}\right)$ and $w_{2}=\ln \left(L / S_{0} e^{X_{t}}\right)$,
Therefore the formula (4.3) becomes

$C\left(t, S_{t}\right)=e^{-i(m-t)} E^{h^{*}}\left[\min \left(\max \left(S_{0} e^{X_{t}+X_{m-t}}-E, 0\right), L-K\right) / F_{t}\right](4.4)$

From (4.1) and (4.4) we obtain

$$
\begin{aligned}
& C\left(t, S_{t}\right) e^{i(m-t)}=S_{t}\left[F\left(w_{2}, h^{*}+1, m-t\right)-F\left(w_{1}, h^{*}+1, m-t\right)\right] \\
& \quad+e^{-i(m-t)}\left[L\left(1-F\left(w_{2}, m-t, h^{*}\right)\right)-K\left(1-F\left(w_{1}, h^{*}, m-t\right)\right)\right] .
\end{aligned}
$$

In this stage the Esscher transform $F$ with parameter $h^{*}$ which is stationary and independent increments, for $w_{1}$ and $w_{2}$ should be computed. It is known that $\widehat{N_{t}}$ has the parameter $\delta t\left(1-\beta\left(h^{*}+1\right)\right)^{-1}$ and using equation (2.3) we obtain $\sum_{i=1}^{n} Y_{i} \sim \exp \left(n, \beta^{*}\right)$ where $\beta^{*}=1-i$

Based on above result and $\widehat{N}_{t}$ parameter, we obtain the following:

$$
\begin{gathered}
F\left(x, h^{*}+1, m-t\right)=\sum_{\substack{n=0 \\
n !}}^{\infty}\left(\frac{\delta t(1-i)}{\beta}\right)^{n} \exp \left(-\delta t\left(\frac{\delta t(1-i)}{\beta}\right)^{n}\right) \\
\cdot \int_{0}^{x} \frac{u^{n-1}(1-i)^{-n}}{(n-1) !} e^{\frac{u}{(1-i)}} d u
\end{gathered}
$$

Assume the integration $\int_{0}^{x} \frac{u^{n-1}(1-i)^{-n}}{(n-1) !} e^{\frac{u}{(1-i)}} d u=\varphi_{1}(n, i, x)$

The distribution functions will be as follows:

$$
\begin{gathered}
F\left(x, h^{*}, m-t\right)=\sum_{n=0}^{\infty} \frac{1}{n !}\left(\delta t\left(1-h^{*} \beta\right)^{-1}\right)^{n} \exp \left(\frac{-\delta t}{\left(1-h^{*} \beta\right)}\right) \\
\cdot \int_{0}^{x} \frac{u^{n-1}\left(1-\frac{1}{i}\right)^{-n}}{(n-1) !} \exp \left(\frac{u}{\left(1-\frac{1}{i}\right)}\right) d u
\end{gathered}
$$

Assume the integration $\int_{0}^{x} \frac{u^{n-1}\left(1-\frac{1}{i}\right)^{-n}}{(n-1) !} \exp \left(\frac{u}{\left(1-\frac{1}{i}\right)}\right) d u=\varphi_{2}(n, i, x)$ Finally, according to (4.6) and (4.7), the Property Claim Services price European call option equation in loss period contract at time $t$ is as follows:

$$
\begin{aligned}
& C\left(t, S_{t}\right)=S_{t} \sum_{n=0}^{\infty} \frac{(\delta(m-t))^{n}}{n !}\left(\frac{1-i}{\beta}\right)^{n} \exp \left(-\left(\delta(m-t)\left(\frac{1-i}{\beta}\right)^{n}\right)\right)+ \\
& {\left[\varphi_{1}\left(n, i, w_{2}\right)-\varphi_{1}\left(n, i, w_{1}\right)\right]+e^{-i(m-t)}\left[L\left(1-F\left(w_{2}, h^{*}, m-t\right)\right)-\right.} \\
& \left.E\left(1-F\left(w_{1}, m-t, h^{*}\right)\right)\right] .
\end{aligned}
$$

\section{THE NUMERICAL RESULT}

Esscher transform has been used in pricing derivative securities using deferent Levy processes, in (Gerber and Shiu, 1994) used different Levy processes to price European call option. In this section, we are going to use exponential Levy process in order to price our chosen derivative security.

Assume that the process $\mathrm{X}(\mathrm{t})=f(x, \beta)+$ ct has $\mu$ as mean per unit $\mathrm{t}$ and $\delta^{2}$ as variance per unit $\mathrm{t}$, also suppose that the third moment parameter per unit time is $\theta^{3}$.

By using Esscher transform we can prove that

$$
M(\mathrm{u}, \mathrm{t} ; \mathrm{h})=E^{h}\left(e^{u X_{t}}\right)=\left(\frac{\frac{1}{\beta}-\mathrm{h}}{\frac{1}{\beta}-\mathrm{h}-\mathrm{u}}\right)^{\mathrm{t}} \mathrm{e}^{-\mathrm{ctu}}, \quad \mathrm{u}<\frac{1}{\beta}-\mathrm{h}
$$

Here we have

$$
\begin{aligned}
& \ln \left(\mathrm{E}\left(\mathrm{e}^{\mathrm{uX}(\mathrm{t})}\right)\right)=\ln (\mathrm{M}(\mathrm{u}, \mathrm{t})) \\
= & \mathrm{t}\left(\mu \mathrm{u}+\frac{\delta^{2} \mathrm{u}^{2}}{2}+\frac{\theta^{3} \mathrm{u}^{3}}{6}+\cdots\right) .
\end{aligned}
$$

Suppose that $\gamma=\theta^{3} / \delta^{3}$, therefore we obtain

$$
\ln \left(\mathrm{E}\left(\mathrm{e}^{\mathrm{uX}(\mathrm{t})}\right)\right)=\mathrm{t}\left(\mu \mathrm{u}+\frac{\delta^{2} \mathrm{u}^{2}}{2}+\frac{\gamma \delta^{3} \mathrm{u}^{3}}{6}+\cdots\right)
$$

From (3.4) and (5.1) we obtain

$$
\begin{aligned}
& \frac{1}{\beta}-c=\mu \\
& \frac{1}{\beta^{2}}=\delta^{2} \\
& \frac{2}{\beta^{3}}=\gamma \delta^{3} .
\end{aligned}
$$

Assume that $\mathrm{i}=0.1, \mu=0.16, \delta=0.32, \gamma=1$ and $\mathrm{S}(0)=$ 100 , here with these assumptions we can have:

$$
\begin{gathered}
c=\frac{1}{\beta}-\mu=\delta-0.16 \\
c=0.32-0.16=0.16
\end{gathered}
$$


Using the above calculations and assumptions, we obtain table (1) which gives the value of European call option for different exercise priceK.

Table 1. Exponential process model option prices

\begin{tabular}{ccccc}
\hline $\begin{array}{c}\text { Exercise } \\
\text { Price }\end{array}(K)$ & \multicolumn{4}{c}{ Time to Maturity } \\
\cline { 2 - 5 }$(=0.25$ & $t=0.5$ & $t=0.75$ & $t=1$ \\
\hline 80 & 11.6612 & 19.7417 & 25.0748 & 28.3199 \\
85 & 9.5077 & 16.0958 & 20.4441 & 23.0899 \\
90 & 7.8428 & 13.2774 & 16.8642 & 19.0468 \\
95 & 6.5372 & 11.0671 & 14.0568 & 15.8760 \\
100 & 5.5001 & 9.3113 & 11.8267 & 13.3573 \\
105 & 4.6667 & 7.9004 & 10.0347 & 11.3333 \\
110 & 3.9900 & 6.7547 & 8.5795 & 9.6899 \\
\hline
\end{tabular}

\section{CONCLUSION}

In conclusion, we supposed that the index which is introduced by a stochastic compound Poisson is processed over the loss period, and the index is re-estimated by exponential time inhomogeneous Levy process factor. In this paper we assume that the formula of pricing European catastrophe options written on the index and used in deriving the Property Claim Services catastrophe insurance option is based on its catastrophe index in loss period contract interval of time.

\section{REFERENCES}

Aase, K. (1999). "An Equilibrium Model of Catastrophe Insurance Futures and Spreads", Geneva Papers on Risk and Insurance Theory 24, 69-96.
Biagini, F., Bregman, Y., and Meyer-Brandis, T (2009). Pricing of catastrophe insurance options written on a loss index with re-estimation.

Chistensen, C.V., and Schmidli, H. (2000) Pricing catastrophe insurance products based on actually reported claims, Insurance: Mathematics and economic 27.

Chang, Carolyn W, Chang, Jack S and Yu, Min-Teh. (1996). "Pricing Catastrophe Insurance Futures Call Spreads: A Randomized Operational Time Approach", The Journl of Risk and Insurance, Vol. 63, No. 4, 599-617.

Dalang, R.C., Morton, A., and Willinger, W. "Equivalent Martingale Measures and No-Arbitrage in Stochastic SecuritiesMarket Models," Stochastics and Stochastic Reports 29 (1990):185-201.

Delbaen, F., and Haezendonck, J. “A Martingale Approach to Premium Calculation Principles in an Arbitrage Free Market,'Insurance: Mathematics and Economics 8 (1989): $269-77$.

Gerber, Hans U. and Elias S.W. Shiu. (1994). Option pricing by Esscher Transforms, Transactions of the Society of Actuaries, Vol. XLVI.

Gerber, Hans U. and Elias S.W. Shiu. (1995) Martingale Approach to Pricing Perpetual American Options, Proceedings of the 4th AFIR International Colloquium, Orlando, April 20-22, vol.

Hogg, R.V., and Craig, A.T. (1995), "Introduction to mathematical statistic", Prentice Hall, Fifth edition.

Muerman, A. (2000). Pricing catastrophe insurance derivatives, Discussion paper 400, financial markets group and the Wharton School.

Murad. Muhammad Amin. S. (2017)." Esscher Transform and Equivalent Martingale in Pricing Derivative Securities" Cihan International Journal of Social Science, vol, 1, No.1, pp.37-44.

Schradin, H.R. (1996).PCS Catastrophe Insurance Options-A new Instrument for managing catastrophe risks", The 6 th AFIR international Colloquium, Nuremberg. 